\title{
Correlacionando genes e doenças através de caminhos metabólicos
}

\author{
Carla Fernandes da Silva ${ }^{1,2}$, Kuruvilla Joseph Abraham ${ }^{3}$ \\ Evandro Eduardo Seron Ruiz ${ }^{2}$
}

\author{
${ }^{1}$ Programa de Pós-Graduação em Computação Aplicada \\ ${ }^{2}$ Departmento de Computação e Matemática, FFCLRP \\ Universidade de São Paulo. \\ ${ }^{3}$ Centro Universitário Estácio de Ribeirão Preto \\ \{carlanandess, evandro\}@usp.br, abrahamkjos@gmail.com
}

\begin{abstract}
One of the main challenges in science is to identify the factors that cause these diseases. Among these factors are the genes. This work will present a methodology to prioritize genes using pathways related to a complex disease. The challenge is to unveil which genes can contribute to triggering a complex disease. The goal is to develop a methodology for prediction of gene-disease through the integration of data related to genes, diseases and metabolic pathways and to eventually discover new genes associated with a disease.
\end{abstract}

Resumo. Um dos principais desafios da ciência é identificar os fatores que causam essas doenças, dentre estes fatores estão os genes. Neste trabalho, será apresentada uma metodologia para priorizar genes e vias metabólicas relacionados a uma doença complexa, com o desafio de descobrir quais os genes podem contribuir para desencadear uma doença complexa. O objetivo é desenvolver uma metodologia para predição de gene-doença através da integração de dados de genes-doencas-vias metabólicas, visando a descoberta de novos genes associado a doença.

\section{Introdução}

Os crescentes avanços genéticos e tecnológicos têm proporcionado uma melhor compreensão das doenças humanas no âmbito geral. Muitas doenças cujas causas eram atribuídas a fatores ambientais e comportamentais, hoje sabe-se que essas doenças possuem também fatores genéticos associados. As doenças cujos fatores protagonizantes são os genéticos, aliado aos fatores ambientais e comportamentais são conhecidas como doenças complexas [Goh and Choi 2012]. Este trabalho aborda o desafio de propor uma metodologia para desvendar quais os genes que podem contribuir para desencadear essas doenças.

Atualmente, podemos notar um grande interesse nas pesquisas relacionadas à predição gênica, ou seja, a identificação funcional de genes em associação a uma doença. Estas pesquisas são facilitadas pela enorme quantidade e variedade de dados genéticos que estão disponíveis em bases públicas de dados. Muitas destas pesquisas consideram informações já existentes de relacionamentos de genes associados a doenças para descobrir novos relacionamentos [Goh et al. 2007, Duarte and Becker 2007, Lee et al. 2008, Lee et al. 2011, Vidal et al. 2011, Ritchie et al. 2015, Menche et al. 2015]. 
Diversos trabalhos na literatura como [Goh et al. 2007, Wu et al. 2008, Li and Agarwal 2009, Barabási 2007, Barrenas et al. 2009, Barabási et al. 2011, Zhou et al. 2014] utilizaram as abordagens de redes complexas para um melhor entendimento dos mecanismos que servem como base para as doenças complexas. Em um trabalho pioneiro, [Goh et al. 2007] criou uma rede de doenças humanas (Human Disease Network - HDN) conectando todas as doenças hereditárias que compartilham um gene causador de doença, de acordo com o banco de dados OMIM. Na rede HDN, duas doença estão conectadas se elas estão associadas a um mesmo gene. Dado que as ligações significam associação genotípica elas poderiam ser usada em conjunto com reações metabólicas.

A união da abordagem de redes gênicas juntamente com a integração de dados de diversos tipos de banco biológicos têm contribuído para diversas descobertas de novos genes para compreensão de doenças complexas. Neste trabalho, é proposta uma metodologia que integra dados sobre genes associados a doenças com informações sobre vias metabólicas para a construção de uma rede de doenças com intuito de selecionar genes que possam explicar um fenótipo da doença. Diferentemente de trabalhos relacionados está proposta inclui vias-metabólicas como fator de associação de doenças.

\section{Metodologia}

A metodologia proposta integra dados sobre genes, doenças e vias metabólicas visando a descoberta de novos genes associados a comorbidades. A construção da metodologia proposta neste projeto pode ser dividida em três etapas, que são:

1. A primeira etapa consiste em extrair as associações de doença-gene do banco de dados KEGG Disease que possuem em torno de 1.704 tipos de doenças humanas ${ }^{1}$. Para cada doença será criada uma lista de genes padronizada de acordo com o a nomenclatura $\mathrm{HGNC}^{2}$. A partir desta lista gene-doença queremos encontrar a sobreposição de genes relacionados com duas doenças ou mais doenças.

2. Na segunda etapa construíremos uma rede doença-doença a partir dos pares de diagnóstico principal e secundário presentes nas Autorizações de Internação Hospitalares (AIHs) extraídos do DATASUS. A rede doença-doença extraída das relações doenças-genes derivadas do KEGG, da etapa anterior, será confrontada com a rede doença-doença extraída das AIHs.

3. A terceira etapa compreende em criar uma rede doença-gene-via metabólica para estudar associações entre genes e doenças através de vias-metabólicas. Procuraremos diferenciar as vias metabólicas gerais das vias específicas e assim esperamos descartar os genes das vias mais gerais por elas fazerem parte de processos biológicos essenciais para a sobrevivência do indivíduo. Esta análise permitirá descobrir se existe uma correlação entre as doenças que compartilhem genes e vias metabólicas entre si. Uma visão sistemátizada da metodologia proposta neste trabalho é apresentada na Figura 1.

\section{Resultados Preliminares}

Até o presente momento, já conseguimos gerar a rede doença-gene que pode ser representada por um grafo bipartido com 1279 vértices correspondentes a doenças, 2692 vértices

\footnotetext{
${ }^{1}$ Última atualização do KEGG Disease em 8 janeiro de 2017.

${ }^{2}$ HUGO Gene Nomenclature Committee
} 


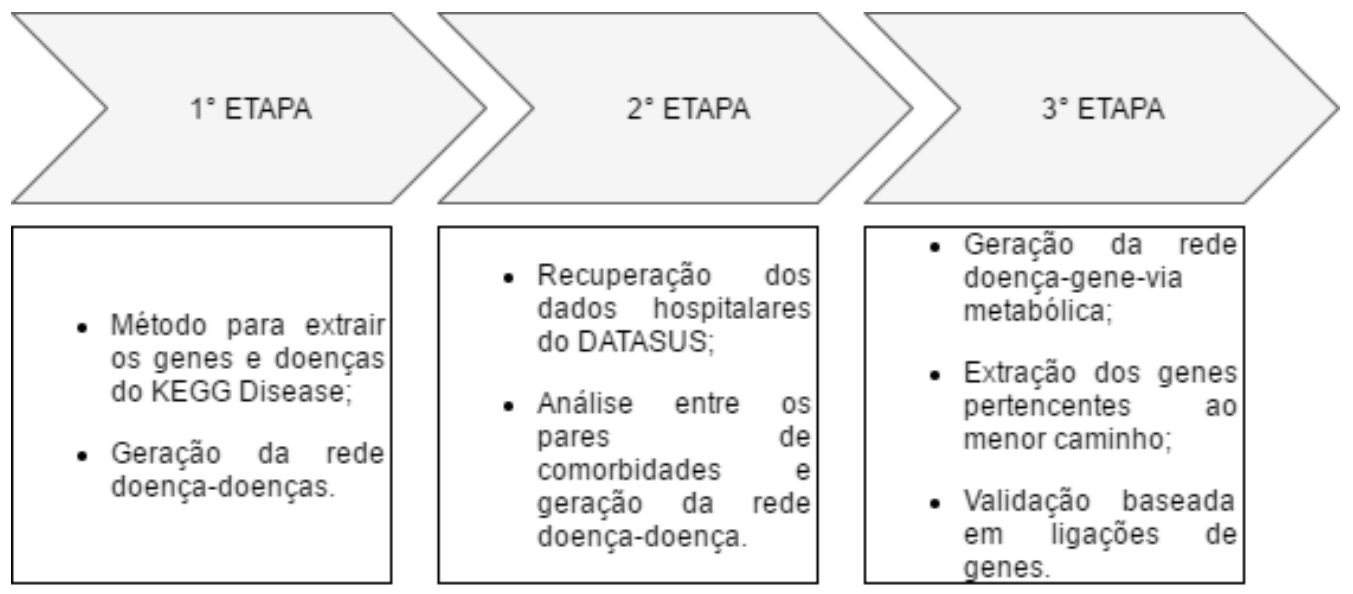

Figura 1. Pipeline de execução das etapas do projeto.

correspondentes a genes e 4432 arestas. A rede doença-gene possui 418 componentes conexos sendo que o maior componente com contém 2778 nós. A partir do grafo doençagene foi gerada um grafo doença-doença, que possui 905 vértices (doenças) e 3480 arestas. Este grafo apresenta 44 componentes conexos sendo que o maior componente apresenta 775 doenças.

A Figura 2(a) ilustra a rede doença-doença gerada a partir do maior componente conexo e com vértices com grau $\geq 2$. O grafo ilustra as relações entre 613 doenças que correspondem onde a 67,7\% das doenças no agrupamento principal, e estão ligadas por 3182 genes (arestas), que representam 91,5\% do mesmo agrupamento. A primeira etapa ainda não está totalmente concluída pois ainda não foi realizada a padronização dos genes e o mapeamento do código de doença do KEGG para CID-10. Pelo gráfico da Figura 2(b) é possível concluir, a partir da distribuição dos graus, que esta rede doença-doença não é uma rede aleatória, o que já se apresenta um resultado original.

Esperamos realizar a padronização via HGNC e compará-la com as relações entre as comorbidades dos registros do SUS.

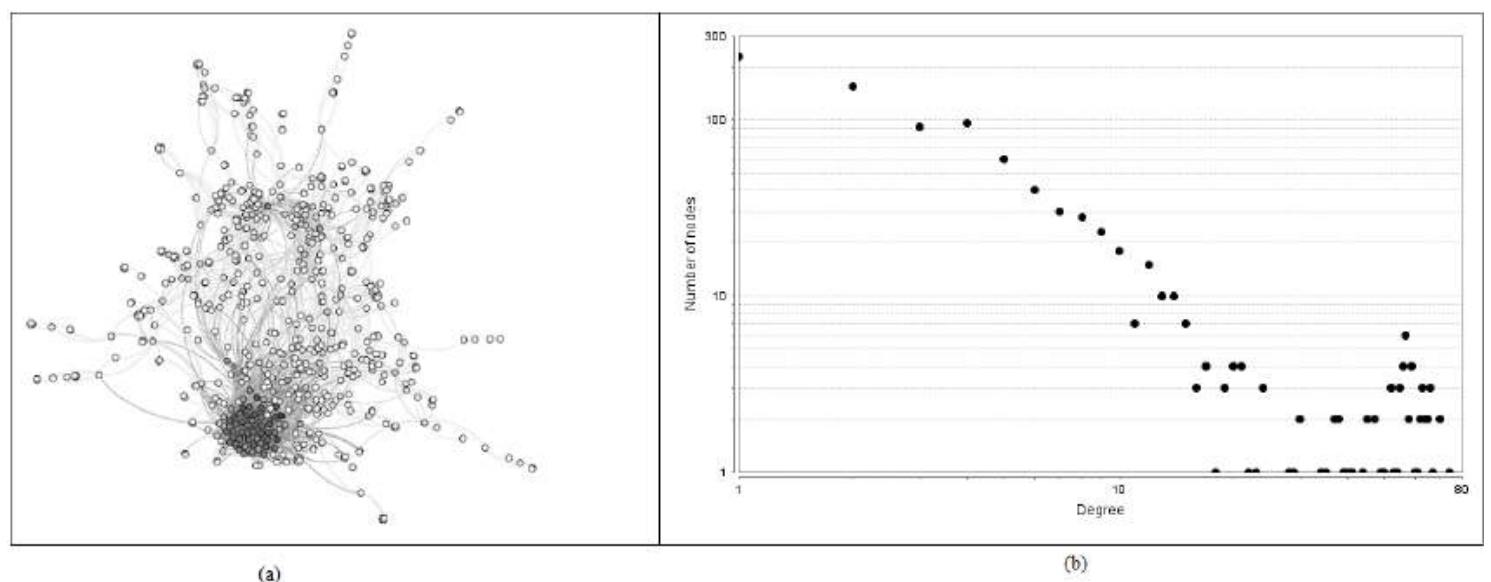

Figura 2. (a) Grafo representando as relações genéticas no KEGG entre 613 doenças, e (b)Distribuição de graus dos vértices. 


\section{Referências}

Barabási, A.-L. (2007). Network Medicine — From Obesity to the "Diseasome". NEJM, 357:404-407.

Barabási, A.-L., Gulbahce, N., and Loscalzo, J. (2011). Network Medicine: A Networkbased Approach to Human Disease. Nature Reviews Genetics, 12(1):56-68.

Barrenas, F., Chavali, S., Holme, P., Mobini, R., and Benson, M. (2009). Network Properties of Complex Human Disease Genes Identified through Genome-Wide Association Studies. PLoS ONE, 4(11):2-7.

Duarte, N. and Becker, S. A. (2007). Global reconstruction of the human metabolic network based on genomic and bibliomic data. Proceedings of the National Academy of Sciences of the United States of America, 104(6):1777-1782.

Goh, K. I. and Choi, I. G. (2012). Exploring the human diseasome: The human disease network. Briefings in Functional Genomics, 11(6):533-542.

Goh, K.-i., Cusick, M. E., Valle, D., Childs, B., and Vidal, M. (2007). The human disease network. Proceedings of the National Academy of Sciences, 104(21):8685-8690.

Lee, D. S., Park, J., Kay, K. A., Christakis, N. A., Oltvai, Z. N., and Barabasi, A. L. (2008). The implications of human metabolic network topology for disease comorbidity. Proceedings of the National Academy of Sciences of the United States of America, 105(29):9880-9885.

Lee, I., Blom, U. M., Wang, P. I., Shim, J. E., and Marcotte, E. M. (2011). Prioritizing candidate disease genes by network-based boosting of genome-wide association data. Genome Research, 21(7):1109-1121.

Li, Y. and Agarwal, P. (2009). A pathway-based view of human diseases and disease relationships. PLOS ONE, 4(2):e4346.

Menche, J., Sharma, A., Kitsak, M., Ghiassian, S. D., Vidal, M., Loscalzo, J., and Barabási, A.-L. (2015). Disease networks. Uncovering disease-disease relationships through the incomplete interactome. Science, 347(6224):1257601.

Ritchie, M. D., Holzinger, E. R., Li, R., Pendergrass, S. A., and Kim, D. (2015). Methods of integrating data to uncover genotype-phenotype interactions. Nature Reviews Genetics, 16(2):85-97.

Vidal, M., Cusick, M. E., and Barabási, A.-L. (2011). Interactome networks and human disease. Cell, 144(6):986-98.

Wu, X., Jiang, R., Zhang, M. Q., and Li, S. (2008). Network-based global inference of human disease genes. Molecular Systems Biology, 4(189):189.

Zhou, X., Menche, J., Barabási, A.-L., and Sharma, A. (2014). Human symptoms-disease network. Nature Communications, 5(May). 